\title{
Universiteit
}

The Netherlands

\section{Excess Mortality in the Aftermath of Hurricane Katrina: A Preliminary} Report.

Stephens Sr, K.U.; Grew, D.; Chin, K.; Kadetz, P.I.; Greenough, P.G.; Burkle Jr, F.M.; ... ; Franklin, E.R.

\section{Citation}

Stephens Sr, K. U., Grew, D., Chin, K., Kadetz, P. I., Greenough, P. G., Burkle Jr, F. M., ... Franklin, E. R. (2007). Excess Mortality in the Aftermath of Hurricane Katrina: A Preliminary Report. Disaster Medicine And Public Health Preparedness, 1(1), 15-20. Retrieved from https://hdl.handle.net/1887/23049

Version: $\quad$ Not Applicable (or Unknown)

License: $\quad$ Leiden University Non-exclusive license

Downloaded from: https://hdl.handle.net/1887/23049

Note: To cite this publication please use the final published version (if applicable). 


\title{
RESEARCH \\ Excess Mortality in the Aftermath of Hurricane Katrina: A Preliminary Report
}

\author{
Kevin U. Stephens Sr, MD, JD, David Grew, MSPH, Karen Chin, MSPH, \\ Paul Kadetz, MSN, MPH, P. Gregg Greenough, MD, MPH, \\ Frederick M. Burkle Jr, MD, MPH, DTM, Sandra L. Robinson, MD, MPH, and \\ Evangeline R. Franklin, MD, MPH
}

\section{ABSTRACT}

Background: Reports that death notices in the Times-Picayune, the New Orleans daily newspaper, increased dramatically in 2006 prompted local health officials to determine whether death notice surveillance could serve as a valid alternative means to confirm suspicions of excess mortality requiring immediate preventive actions and intervention.

Methods: Monthly totals of death notices from the Times-Picayune were used to obtain frequency and proportion of deaths from January to June 2006. To validate this methodology the authors compared 2002 to 2003 monthly death frequency and proportions between death notices and top 10 causes of death from state vital statistics.

Results: A significant (47\%) increase in proportion of deaths was seen compared with the known baseline population. From January to June 2006, there were on average 1317 deaths notices per month for a mortality rate of 91.37 deaths per 100,000 population, compared with a 2002-2004 average of 924 deaths per month for a mortality rate of 62.17 deaths per 100,000 population. Differences between 2002 and 2003 death notices and top 10 causes of death were insignificant and had high correlation.

Discussion: Death notices from local daily newspaper sources may serve as an alternative source of mortality information. Problems with delayed reporting, timely analysis, and interoperability between state and local health departments may be solved by the implementation of electronic death registration. (Disaster Med Public Health Preparedness. 2007;1:15-20)

Key Words: excess mortality, natural disasters, hurricane Katrina, public health system, death notice surveillance, mortality data, health statistics

Editors' Note: After not experiencing a major public health emergency in almost 100 years, the US is relearning the stark realities that occur when a public health system is compromised and the pulse of a community is temporarily lost. In the chaotic aftermath of Hurricane Katrina the impact on health, through its influence on infrastructure and the determinants of health, subtly began to rear its ugly head. When the daily capacity to evaluate and monitor health indices fails, as it has in New Orleans, morbidity and mortality remain unnoticed and uncounted. Predictably, vulnerable populations suffer the most.

Stephens and his colleagues, alerted by the concerns of the citizenry, again took the pulse of the community and found that the rate of death notices, as just 1 "imperfect" measure of excess mortality, was suspiciously elevated. Is this an ideal population-based study? No, but both the question and the strength of this preliminary report are something that disaster medicine specialists have been struggling with for decades. What do we need to know to prevent needless mortality and morbidity while the public health system is recovering? How do we derive the essential information to guide health relief efforts and measure the interaction between the human host and the compromised environment to prevent further harm when the traditional system of assessing mortality is debilitated? The entire postdisaster surveillance system may have only 1 person doing essentially all of the tasks. What does this lone person do when resources are limited?

Our disaster medicine colleagues who respond to catastrophic public health emergencies worldwide have educated us on the nuances of the prolonged effect that such disasters have on the community. Following the prototypical wars that destroyed their countries' public health infrastructure, the decay factors that cause preventable deaths continued for many years after the shooting had stopped. Years later, retrospective studies recorded many more deaths from indirect causes, and those that suffer the most typically are women, children, old people, and people with disabilities. Ninety percent of excess deaths were preventable. 
The US is not a developing country, but the uncomfortable reality of the public health impact and management of Katrina is painfully similar. The authors' study has exposed that glaring deficiency — that an attentive and proactive surveillance and response mechanism is justifiably obligated from state and federal agencies.

$\mathrm{H}$ ow can dependable mortality data be accessed when the usual means of data collection have been profoundly disrupted? Mortality data and health statistics reports provide public health officials with critical insight into the health status of a population. These data provide key information for public health research, facilitate long-term surveillance, and are commonly the basis for health interventions. ${ }^{1}$

The National Association for Public Health Statistics and Information Systems is partnering with the National Center for Health Statistics in a cooperative agreement to upgrade all 50 states from paper-based to electronic death registration systems (EDRS). ${ }^{2}$ A nationwide EDRS will facilitate rapid reporting and interoperability between local, state, and national health agencies, and will streamline the vital records request process (G. Land, personal communication, July 7, 2006 ). This system is not currently in place to address the immediate public health issues from future disasters in Louisiana. ${ }^{3}$

Under normal circumstances, mortality rates are derived from death certificates registered at each state's office of vital records. Before Hurricane Katrina, the Louisiana Department of Health and Hospitals issued an annual health report card, which included statistical reports across various health indices, serving as an overall evaluation of Louisiana's health. The most recently released health report card was submitted to the state legislature in March 2006 for the 2005 report; however, all of the mortality data presented in the state's report date from 2003. ${ }^{4}$

The Louisiana Department of Health and Hospitals Office of Vital Statistics is responsible for processing requests for vital record certificates, including birth, death, and marriage certificates, as well as generating statistical reports. ${ }^{5}$ The department's ability to function at full capacity was interrupted by Hurricane Katrina. Only $80 \%$ of vital record certificates were moved from the flooded basement of the New Orleans State Office Building to a floor higher in the building before the flooding. The majority of these certificates were birth records. The Office of Vital Statistics is operating at nearly half the pre-Katrina capacity, with a reduction from 87 employees to a current staff of 51 employees. Furthermore, a majority of this workforce is temporary and/or new employees. Although the staff has been significantly reduced, the requests for documents have markedly increased from 300,000 requests in 2004 to 534,936 requests within the last year. ${ }^{6}$ Operations for the Office of Vital Statistics have been relocated from New Orleans since the storm and are now divided between Baton Rouge $^{6}$ and Metairie. ${ }^{7}$ Consequently, the ability of the Louisiana Department of Health and Hospitals Office of Vital Statistics to generate accurate and timely statistical reports, in light of these myriad factors, is compromised.

The floodwaters caused by Hurricane Katrina have had a lasting impact on the health system of New Orleans and its surrounding parishes. Only 15 of 22 area hospitals have reopened, with less than half the number of prestorm beds. ${ }^{8}$ A significant portion of the population is still living in substandard conditions, contributing to the reported pervasive, unmitigated stress among residents. ${ }^{9,10}$ As such, health officials fear there will be increases in morbidity and mortality. ${ }^{8}$ Given the compromised mechanism for registering local deaths, there is a demonstrated need for alternative means of generating mortality information and indices. Death notices in the Times-Picayune, the greater New Orleans daily newspaper, increased dramatically in 2006. ${ }^{10}$ In the absence of an EDRS and current, verified vital statistics from the state, the present study attempts to use extrapolated daily newspaper death notices as a valid alternative to the conventional but deficient registration system, and in so doing, determine a workable mortality rate for greater New Orleans in the aftermath of Hurricane Katrina.

\section{METHODS}

The source for 2006 mortality data was the Times-Picayune, which maintains a Web site that contains a 6 -month backlog of death notices. ${ }^{11}$ The Times-Picayune receives death notices via a passive data collection mechanism: funeral directors and families of deceased not using funeral homes may submit death notices via e-mail or fax. Death notices for the years 2002 to 2003 were obtained from the NewsBank, Inc, online database through the New Orleans Public Library ${ }^{12}$ to establish a baseline mortality rate. Death notices from the Times-Picayune were counted per month for the years 2002 to 2003 and for the months of January to June 2006.

For a standard of comparison, the number of deaths were obtained from the Louisiana Office of Public Health, State Center for Health Statistics for the greater New Orleans area that includes Orleans, Jefferson, Plaquemines, Saint Bernard, Saint Charles, Saint James, Saint John the Baptist, Saint Tammany, Tangipahoa, and Washington parishes. Monthly mortality data representing the top 10 causes of death for the 
greater New Orleans area were obtained for the years 2002 to 2003 from the Louisiana Department of Health and Hospitals Health Statistics Center. These datasets were extrapolated from data available on the department's Web site. ${ }^{13}$ Top 10 causes of death is used in place of total mortality because data on total mortality were not available at the parish level.

In a stable, open population, an estimate of the mid-year population serves as the denominator of a mortality rate. Therefore, mid-year population estimates were used for denominator data for the 2 baseline years, 2002 and $2003 .{ }^{14}$ At the time the present study was carried out, the only population estimate available for greater New Orleans was from January 2006. ${ }^{9}$ Therefore, this population was used to represent the denominator for the mortality calculations from January to June 2006.

To limit the effects of potential confounders on the results, the authors excluded death notices that reported an out-ofstate death, an out-of-greater New Orleans (but still within Louisiana) death, a death that occurred during Hurricane Katrina but was reported after January 1, 2006, or a duplicate entry death. Because removing all of these entries would require reading each death notice in detail, the authors sampled 1 week of death notices in the middle of each month, totaled the number of death notices that satisfied exclusion criteria, and averaged the number over the 6 -month period.

To determine whether the newspaper death notice and official state datasets were correlated, the authors compared mortality rates during the period of 2002 to 2003 for each dataset. To detect any significant change in mortality across 2002 to 2003, mortality rates from 2002 were compared to 2003 for each data source. These analyses were performed separately. Death notices were compared with death notices and state data were compared with state data across the 2-year period to test the integrity of the data source. Mortality rates derived from the Times-Picayune death notices in the first 6 months of 2006 were compared with those from 2002 to 2003 (pre-Katrina). Data entry and tests of statistical significance and correlation were done using Microsoft Excel 2002 (Microsoft, Inc, Redmond, WA).

\section{RESULTS}

Total death notices from January to June 2006 and death notices meeting exclusion criteria during the same period are described in Table 1 . The resulting number for mortality rate calculation is included in Table 2 .

Average monthly mortality rates for 2002 to 2003, calculated from Louisiana state data and Times-Picayune death notices using the greater New Orleans pre-Katrina population estimates from those years, are compared in Figure 1. The $r$ value for correlation between the mortality rates derived from the 2 datasets is .6563 , representing a significant (large positive) correlation.

The strong correlation gave validity to the death notices as a reasonable alternative to determine post-Katrina mortality and make comparisons with pre-Katrina mortality. A baseline average of deaths per month from January to June and the mortality rates based on pre-Katrina greater New Orleans population estimates are compared with mortality rates during the same months in 2006 on the post-Katrina greater New Orleans population estimate. Confidence intervals for mean mortality rates were calculated for both periods (Table 2 ). The paired Student $t$ test was used to test significance between the sample means. The $t$ value was not statistically significant $(P=.354)$, proving the hypothesis that there was no difference between the means of the 2 datasets.

The post-Katrina mortality rate for the first 6 months of 2006 was approximately 91.37 deaths per 100,000 population; compared to the pre-Katrina population mortality rate of 62.17 deaths per 100,000 population, this represents an average $47 \%$ increase from the baseline mortality, suggesting a marked increase in indirect (excess) deaths postdisaster (Figure 2). Although the confidence interval around the 2006 mean is wide, there is little overlap with the 2002 to 2003 confidence interval, suggesting a significant difference in the mortality distributions between the 2 populations.

\section{DISCUSSION}

The significant increase in proportion of deaths in the first 6 months of 2006 supports the civilian population's suspicions about the enduring health consequences of the hurricane. This major natural disaster resulted in a severe compromise of the public health infrastructure, the loss of health care facil-

\section{TABLE}

Frequency of Death Notices by Inclusion and Exclusion Criteria, 2006

\begin{tabular}{|cccccccc} 
& January & February & March & April & May & June \\
$\begin{array}{l}\text { Total death notices } \\
\text { Excluding }\end{array}$ & 1589 & 1301 & 1418 & 1214 & 1194 & 1185 \\
$\begin{array}{c}\text { Katrina deaths } \\
\text { Excluding }\end{array}$ & 1558 & 1270 & 1387 & 1183 & 1163 & 1154 \\
$\begin{array}{c}\text { out-of-LA deaths } \\
\text { Excluding duplicate }\end{array}$ & 1427 & 1139 & 1256 & 1052 & 1032 & 1023 \\
$\begin{array}{c}\text { entries } \\
\text { Excluding out-of-10 } \\
\text { parish deaths }\end{array}$ & 1206 & 918 & 1035 & 831 & 811 & 802 \\
\hline
\end{tabular}


TABLE 2

Frequency of Death per Population and Mortality Rates, Pre- and Post-Katrina, Times-Picayune Death Notices

\begin{tabular}{|c|c|c|c|c|c|c|c|c|}
\hline & \multicolumn{4}{|c|}{ 2002-2003 } & \multicolumn{4}{|c|}{2006} \\
\hline & $\begin{array}{l}\text { Av No. of } \\
\text { Deaths }\end{array}$ & $\begin{array}{l}\text { Total NO Metropolitan } \\
\text { Population }\end{array}$ & $\%$ & $\begin{array}{c}\text { Mortality Rate } \\
\text { (deaths/100,000) }\end{array}$ & $\begin{array}{l}\text { No. of } \\
\text { Deaths }\end{array}$ & $\begin{array}{l}\text { Total NO Metropolitan } \\
\text { Population }\end{array}$ & $\%$ & $\begin{array}{c}\text { Mortality Rate } \\
\text { (deaths/100,000) }\end{array}$ \\
\hline Jan & 1037.5 & $1,481,393$ & 0.070 & 70.04 & 1108 & 914,745 & 0.121 & 121.13 \\
\hline Feb & 864.5 & $1,481,393$ & 0.058 & 58.36 & 820 & 914,745 & 0.090 & 89.64 \\
\hline Mar & 986.5 & $1,481,393$ & 0.067 & 66.59 & 937 & 914,745 & 0.102 & 102.43 \\
\hline Apr & 887 & $1,481,393$ & 0.060 & 59.88 & 733 & 914,745 & 0.080 & 80.13 \\
\hline May & 885 & $1,481,393$ & 0.060 & 59.74 & 713 & 914,745 & 0.078 & 77.95 \\
\hline Jun & 865 & $1,481,393$ & 0.058 & 58.39 & 704 & 914,745 & 0.077 & 76.96 \\
\hline Mean with $95 \% \mathrm{Cl}$ & & & & $\begin{array}{c}62.17 \\
(95 \%-7202)\end{array}$ & & & & $\begin{array}{c}91.37 \\
(95 \%)\end{array}$ \\
\hline
\end{tabular}

Abbreviations: NO, New Orleans; $\mathrm{Cl}$, confidence interval.

ities and the ability to deliver care, and a chaotic shift in a major metropolitan population. Furthermore, it disabled the ability of the state to perform optimal evaluation and monitoring studies. Such sequelae characteristically prolong public health emergencies and allow for conditions that are ripe for indirect effects leading to increased mortality and morbidity, data that are often unnoticed and uncounted.

Excess death studies, especially those performed during large-scale public health emergencies, risk inherent loss of the stringent evaluation and monitoring standards that are expected during less chaotic times. Whereas death rate reports may prove alarming, they must first alert decision makers to rally resources to intervene where prevention of further deaths are most likely and to develop robust evaluation and monitoring programs to identify and verify the exact nature of possible excess mortality and the most vulnerable of subpopulations experiencing mortality and morbidity. There is an urgent need to understand the

\section{FIGURE 1}

\section{Comparison of average monthly mortality rates for 2002-2003, Louisiana state data vs Times-Picayune death notices}

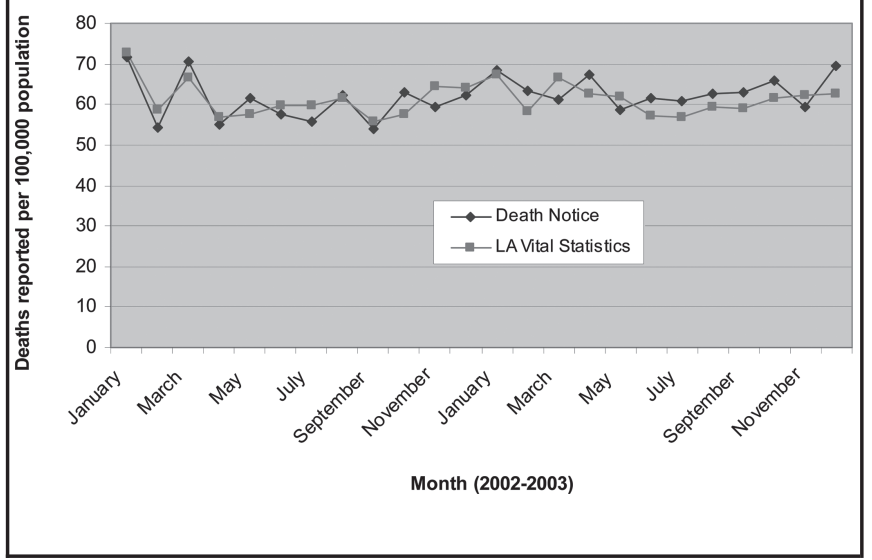

etiology of the problem so that local, state, and federal health agencies can better prepare for and anticipate future public health emergencies. The present study raises this concern in the post-Katrina greater New Orleans population and suggests an urgent need for further study to investigate the causes and age distribution of these excess deaths. It is a call to action to federal and Louisiana state health authorities to direct the necessary resources to determine and monitor these causes.

Immediately following disasters, public health officials need reliable sources of mortality information to determine direct and indirect consequences, particularly when traditional health information systems are debilitated. In this study, an alternative source of mortality information-death notices published in the daily metropolitan newspaper, the TimesPicayune - was found to correlate highly with mortality data from the conventional state health information system in the pre-Katrina population. The $r$ value of .66 likely underestimates the strength of the correlation because there is a slight curvilinear relationship between the 2 datasets due to the seasonal variability of the deaths over the year. The authors

\section{FIGURE 2}

\section{Comparison of average mortality rates between January-June 2006 and January-June 2002-2003, Times-Picayune death notices}

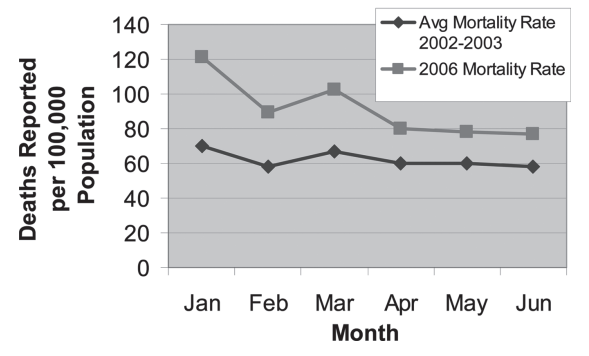


believe that this study validates this alternative source in this population, and was thus a reliable source of mortality information during a period in a disaster when the traditional mortality data-collecting mechanism was incapacitated. Furthermore, death notice monitoring provided real-time mortality information well ahead of official state health information mortality data, giving impetus to the Louisiana health departments to adopt an interoperable statewide EDRS to rapidly assess and monitor mortality.

\section{Strengths}

The exclusion criteria of this study eliminated 2006 death notices that did not occur in the specified geographic area of the study or within the specified time frame of the study (Table 1). This was done to eliminate death notices that may artificially inflate the 2006 mortality rate calculation. Eliminating death notices by using strict exclusion criteria would likely result in a conservative estimation of true mortality rates in the first 6 months of 2006. It should be noted that before Katrina, the Times-Picayune offered both paid and free death notices, whereas after the storm they only offered paid death notices. This difference would also likely result in an artificially reduced number of death notices and minimize the likelihood of an inflated mortality rate in the first 6 months of 2006 .

\section{Limitations}

The data source for current mortality, the Times-Picayune, uses a passive data collection system. This would likely result in underreporting of the true mortality because there are deaths that occur in the area that are not published as death notices in the Times-Picayune. Underreporting of mortality would result in an underestimation of current mortality rates, making the results of this study even more alarming.

The study source for the population of greater New Orleans provides only an estimate for January 2006, and the authors necessarily used this population estimate in the denominator data for mortality rate calculations for each month of 2006. However, according to recent data, the population of greater New Orleans has been exceptionally dynamic and growing steadily (demonstrated in data collected through May 2006). 9,15 If the population of greater New Orleans did increase in the first 6 months of 2006, the calculations of mortality rates will overestimate the true mortality rate over the first 6 months of 2006 by virtue of underestimating the true population.

There may be demographic differences, particularly in age distribution, between the pre-Katrina and post-Katrina populations of greater New Orleans. The 2006 population of greater New Orleans may have a disproportionate number of older adults and therefore a higher death rate. The authors did not adjust for age in their mortality calculations. The degree to which changing demographics affected the results of this study cannot be known until further studies investigating the current demographics of greater New Orleans are carried out.

\section{CONCLUSIONS}

A significant increase in the mortality rate for the first 6 months of 2006 substantiates the deleterious effects of enduring health consequences resulting from a major disaster. This must be understood as an urgent call for further studies and subsequent interventions. The authors believe that the underlying causes of the increased mortality rates within the greater New Orleans' population are complex, multifactorial, and persistent. This disaster severely compromised the public health infrastructure. It is suggested that a destroyed or poorly recovered public health infrastructure, which normally would be able to identify health problems and protect the health of a population, has in fact contributed to excess mortality.

Finally, the necessity to set standards that will open the lines of communication across public health agencies in the event of a disaster is clearly indicated. ${ }^{16}$ Interagency communication can deteriorate rapidly in the midst of a disaster; each office is often solely focused on meeting its own needs and thereby unavailable to provide information across jurisdictions. Offices were flooded, paper records had to be rerouted, and only a fraction of office staff returned to work. This confluence of events reveals the urgent need for states to adopt electronic reporting systems.

\section{About the Authors}

Kevin U. Stephens Sr is with the New Orleans Health Department; David Grew is with the Tulane Medical School and the Tulane School of Public Health and Tropical Medicine; Karen Chin and Paul Kadetz are with the Tulane School of Public Health and Tropical Medicine; P. Gregg Greenough and Frederick M. Burkle Jr are with the Harvard Humanitarian Initiative, Harvard University; and Sandra L. Robinson and Evangeline R. Franklin are with the New Orleans Health Department.

Address correspondence and reprint requests to Kevin U. Stephens Sr, MD, JD, Director, New Orleans Health Department, 1300 Perdido St, Room 8E18, New Orleans, LA 70112 (e-mail: kustephens@cityofno.com).

Received and accepted for publication April 6, 2007.

ISSN: 1935-7893 @ 2007 by the American Medical Association and Lippincott Williams \& Wilkins.

DOI: 10.1097/DMP.0b013e3180691856

\section{REFERENCES}

1. Steering Committee Report. Toward an electronic death registration system in the United States: report of the Steering Committee to Reengineer the Death Registration Process. Am J Forensic Med Pathol 1998;19:234-241.

2. National Association for Public Health Statistics and Information Systems. Web site. http://www.naphsis.org. Accessed April 4, 2007.

3. Marek A. Learning the hard lessons of Katrina: why things were even worse than you ever knew. US News EJ World Report. May 28, 2006. http:// www. usnews.com/usnews/news/articles/060605/5neworleans.htm. Accessed April 3, 2007.

4. Cerise FP. 2005 Louisiana Health Report Card. March 2006. Louisiana Department of Health and Hospitals Web site. http://www.dhh.louisiana. gov/offices/publications/pubs-275/Health\%20Report\%20Card\%202005.pdf. Accessed April 3, 2007.

5. Office of Public Health Director. State Registrar/Vital Records and Statistics Web site. http://www.dhh.louisiana.gov/offices/?ID=252. Accessed April 3, 2007. 
6. Shuler M. Katrina still burdens state registry. February 24, 2007. The AdvocateWBRZ ABC News 2 Louisiana Web site. http://www.2theadvocate.com/news/ neworleans/6053061.html. Accessed April 3, 2007.

7. New phone numbers for vital records. Louisiana Department of Health and Hospitals Web site. http://www. dhh.louisiana.gov/news.asp? ID=1 EDDetail= 784EAArch=2006. Accessed April 3, 2007.

8. Beggren RE, Curiel TJ. After the storm: health care infrastructure in post-Katrina New Orleans. N Engl J Med. 2006;354:1549-1552.

9. The Katrina Index. Tracking Recovery of New Orleans \& The Metro Area. Greater New Orleans Community Data Center. http://www.gnocdc. org/KI/KatrinaIndex.pdf. Accessed April 3, 2007.

10. Weeks L. New Orleans locals think Katrina's toll is still rising: surge in deaths blamed on storm-related stress. Washington Post. February 19, 2006:A03.
11. Death Notices \& Guest Books. nola.com Web site. http://obits.nola.com/ NOLA/DeathNotices.asp. Accessed April 10, 2006.

12. New Orleans Public Library. Newsbank Inc Web site. http://infoweb. newsbank.com. Accessed April 3, 2006.

13. Records and Statistics. State Center for Health Statistics. http://www. dhh.louisiana.gov/offices/?ID=275. Accessed April 10, 2006.

14. County population estimates. US Census Bureau Web site. http://www. census.gov/popest/counties. Accessed April 10, 2006.

15. Chapman J, Dailey M. Post-disaster population estimates. http://www. dhh.louisiana.gov/offices/?ID=88. Accessed April 10, 2006.

16. Vital Records and Statistics re-engineering. National Association for Public Health Statistics and Information Systems Web site. http:// www.naphsis.org/projects/index.asp? $=0 \mathbb{E} b i d=393$. Accessed April 4, 2007. 